\title{
O PRIMEIRO ANO DE EXISTÊNCIA DA BIBLIOTECA MUNICIPAL DE CAMPINA GRANDE-PB: AS VOZES NA BORBOREMA
}

\section{THE FIRST YEAR OF EXISTENCE OF THE MUNICIPAL LIBRARY IN CAMPINA GRANDE-PB: VOICES IN BORBOREMA}

Danielly Vieira Inô*

\begin{abstract}
Resumo: Neste trabalho, retomamos um momento da história da Biblioteca Pública Municipal de Campina Grande-PB (BPMCG), focalizando principalmente o seu processo de criação (ocorrido em 1938) e seu primeiro ano de funcionamento, procurando responder às seguintes questões: qual a história da BPMCG e de que forma essa instituição se inseriu no contexto cultural da cidade nos primeiros anos após sua fundação? Quem foram os grupos sociais que defenderam a sua criação? Que motivações os levaram a propor essa criação? De que maneira as autoridades competentes e a população em geral receberam a ideia? Desta forma, observamos seu modo de inserção na sociedade naquele período e as representações construídas em torno da instituição. Para tanto, nosso corpus foi constituído por documentos oficiais publicados no jornal $A$ Voz da Borborema, que registram como se deu o processo de fundação/inauguração desse espaço de leitura, bem como notícias que abordavam a repercussão desse fato na sociedade.
\end{abstract}

Palavras-chave: biblioteca pública. História. Leitura.

Abstract: In this work, we have resumed a moment of the story of Campina Grande' s municipal public library (BPMCG), focusing mainly on its process of creation (occured in 1983) and its first year of working, as an attempt to answer the following questions: What's the history of the BPMCG and how does this institution was inserted in the cultural context of the city in the First years after its foundation? What were the social groups that defended its creation? Which were the motivations that led them to propouse the creation? How did the competent authorities and the population in general receive the Idea? Therefore, we have observed its insertion mode in the society on that period and the representations built around the institution. For this purpouse, our corpus was composed by oficial documents published on "A voz da Borborema" news, that register how the foundation/ opening process of this reading space was, as well as the news that approched there percussion of this fact in the society.

Keywords: public library. History. Reading.

\section{Introdução}

As bibliotecas, espaços criados para armazenar as obras produzidas, mas também para protegê-las e difundi-las, tiveram sempre um destino incerto, entre a construção e a destruição, e finalidades distintas - entre a guarda do livro como tesouro e a abertura para o público. Ao tentar recuperar a história de instituições dessa natureza, raramente temos acesso a informações precisas e documentos oficiais que comprovem as circunstâncias de sua criação, as motivações (econômicas, sociais, culturais e históricas) para sua fundação e o modo como a sociedade reagiu à ideia de ter uma biblioteca pública. Essa mesma condição se aplica à Biblioteca Pública Municipal de

\footnotetext{
* Doutora em Linguistica pela Universidade Federal da Paraíba. Atualmente é professora de Linguística do Departamento de Letras da Universidade Estadual da Paraíba (campus VI). Tem experiência na área de Letras, com ênfase em Linguagem e Ensino, atuando principalmente nos seguintes temas: produção textual, leitura, história da leitura e ensino.
} 
Campina Grande-PB, fundada em 1938 e sobre a qual há poucos registros que comprovem as diferentes etapas pelas quais passou essa instituição ao longo do tempo.

O presente artigo - que se insere na linha de estudos denominada História da Leitura (CHARTIER, 1991, 1996; 2002; 2003; 2009) e entende leitura como prática social - discute as seguintes questões: qual a história da Biblioteca Pública Municipal de Campina Grande-PB (BPMCG) e de que forma essa instituição se inseriu no contexto cultural da cidade no primeiro ano após sua fundação? Quem foram os grupos sociais que defenderam a criação da biblioteca? Que motivações (intelectuais, políticas, econômicas) os levaram a propor essa criação? De que maneira as autoridades competentes e a população em geral receberam a ideia? O nosso objetivo é, portanto, registrar a história da Biblioteca Municipal de Campina Grande-PB no seu primeiro ano de existência, buscando compreender as relações entre o ato de fundação da biblioteca e o contexto sócio-histórico-cultural da cidade naquele momento.

Para tanto, nosso corpus foi constituído por documentos oficiais publicados no jornal A Voz da Borborema, que registram como se deu o processo de fundação/inauguração desse espaço de leitura, bem como notícias que abordavam a repercussão desse fato na sociedade campinense. Nesse sentido, observamos seu modo de inserção na sociedade naquele período e as representações construídas em torno da instituição. Paralelamente, refletimos sobre como a história dessa Biblioteca se relaciona com o percurso seguido por outras instituições dessa natureza - percurso este que pode revelar muito sobre o modo como hoje lidamos com esses espaços de leitura (seja como leitores ou não).

\section{Um contexto para uma biblioteca}

O jornal campinense $A$ Voz da Borborema foi fundado em 1937 e pertencia à família de Argemiro de Figueiredo, interventor federal no Estado da Paraíba naquele momento (CABRAL FILHO, 2009). Mais especificamente, esse periódico era dirigido pelo advogado Acácio Figueiredo, irmão do interventor e também de Bento Figueiredo, então prefeito de Campina Grande. Isso explica muito do teor das matérias publicadas e da escolha dos articulistas que escreviam para o jornal, como será discutido a seguir.

Pelo que se pode inferir através de informações dispersas no jornal $A \mathrm{Voz}$ da Borborema, havia em Campina Grande-PB, no final dos anos 30 (séc. XX), certa elite cultural letrada, que não apenas consumia leitura, como também produzia/escrevia. Não pretendemos incorrer no erro de construir uma dicotomia e afirmar que apenas essa camada da população consumia e produzia material de leitura, principalmente porque os outros grupos sociais, sem dúvida, possuíam sua forma de se relacionar com a cultura escrita - seja lendo ou produzindo, para trabalho ou lazer (ver, por exemplo, os folhetos de cordel vendidos nas feiras, frequentadas por pessoas de diferentes grupos, ou ainda os cartazes de divulgação de eventos). Contudo, a divulgação de idéias através dos jornais impressos parece mesmo ter ficado a cargo da elite intelectual da cidade, pois era ela, inclusive, a responsável por fundar e administrar esses meios de comunicação naquele período.

$\mathrm{Na}$ perspectiva defendida por essa camada da população, era preciso fazer circular em outros espaços e grupos, de maneira mais efetiva, essa cultura letrada produzida por ela, para que assim os valores promovidos por esse grupo pudessem alcançar diferentes camadas da população e, indiretamente, contribuir para a modernização da cidade através da mudança de hábitos que a instrução/educação promoveria. 
Segundo Oliveira (2009, p. 203),

A relação estabelecida entre alfabetização e higiene, cultura escolar e saúde, era visível e dizível nos discursos [...] de muitos articulistas locais, um apelo feito para que os responsáveis ensinem os conhecimentos vinculados ao corpo e à saúde, carregado de um forte sentido normativo e moralizador.

Mas, e quanto à existência de bibliotecas? Essa elite cultural conservava em suas casas as suas próprias bibliotecas particulares, fato que será confirmado depois, através das doações feitas por cidadãos ilustres à biblioteca municipal. No entanto, não sabemos afirmar ao certo se havia bibliotecas destinadas ao público em geral, que ainda estivessem em funcionamento nos meses que antecedem a inauguração da Biblioteca Pública Municipal.

As informações coletadas no jornal $A$ Voz da Borborema, no início do ano em que a BPMCG é fundada, levam a crer que a cidade já não possuía mais um espaço que cumprisse com a função de uma biblioteca. Em janeiro de 1938, foi publicado no jornal A Voz da Borborema o seguinte apelo:

\section{Club Campinense de Cultura}

Eu vi o artigo appello do dr. Hortensio Ribeiro e a mocidade campinense enthusiasmada.

Interprete dos anseios de cultura que uma roda assídua proclamava, o intellectual n. 1 da cidade, ergueu primeiro o grito conclamando os jovens estudiosos a se congregarem, estimulando-se mutuamente no cultivo das letras e da sciencia.

Interrompera-se ha já algum tempo as tradições culturaes de nossa terra, onde nunca faltara uma associação de estudos entre as quaes cito com saudade o Gabinete de Leitura 7 de Setembro.

Toda uma geração estava intellectualmente desamparada. Mas o ardente enthusiasmo com que foi recebida a nota do dr. Hortensio correspondeu ao vigor do appello. E a minha geração não continuará desmembrada e inutil demonstrando no quanto deve o quanto póde.

Campina Grande necessita de uma vida intellectual á altura de sua vida econômica. Já conta por milhar o número de alumnos de suas escolas. Tem já um bom jornal como esta "Voz da Borborema". Professores, advogados, médicos, dentistas, engenheiros, etc, são já em grande numero. Tudo isto reclama uma bibliotheca, um salão de conferencias, um estimulo á cultura. Iniciemos hoje o anno novo combinando, ajustando um Club de Cultura, para que tenhamos neste 38 de tantas esperanças, um ambiente intellectual mais arejado e mais lucido.

O toque de reunir já foi dado, resta agora cerrar fileiras com a força estuante de nossa mocidade.

Ergamos o nível intelectual campinense instituindo entre nós um centro de cultura. (MELLO, Honorio de. Jornal Voz da Borborema, 01/01/1938, p. 5. Grifos do autor).

É interessante observar dois dados importantes nesse texto: o primeiro deles é a referência à existência do Gabinete de Leitura 7 de Setembro ${ }^{1}$ na cidade, o qual havia

\footnotetext{
${ }^{1}$ O Gabinete de Leitura Sete de Setembro situava-se, segundo Costa (2012), na Rua Maciel Pinheiro, onde "estavam localizados desde as primeiras décadas do século XX, além dos primeiros cinemas [...], 'Apolo' e 'Fox', teatros, os mais elegantes clubes sociais" (p. 31), e onde eram realizadas feiras, festas de carnaval e procissões.
} 
sido extinto, deixando "toda uma geração [...] intelectualmente desamparada", como afirma o autor, Honorio de Mello. O Gabinete surgiu quando

[...] um grupo de intelectuais, ansiosos por socializarem suas idéias e valores, criou uma instituição, que durante pouco mais de 20 anos centralizou boa parte das atividades artísticas e culturais do município, pois dentro de sua estrutura organizacional, possuiu biblioteca, jornal, revista, escola pública gratuita, etc. promovendo sempre festas cívicas e literárias, para um público específico: uma elite política e econômica. (GAUDÊNCIO, 2012, p. 54-55)

A biblioteca mantida pelo Gabinete é considerada a primeira biblioteca pública de Campina Grande, pois não apenas os sócios dessa instituição poderiam ter acesso a ela. Contudo, considerando o grau de escolaridade de boa parte da população, é provável que apenas uma parcela pequena usufruísse desse espaço.

Além do importante Gabinete de Leitura 7 de Setembro, pelo menos duas das instituições já citadas - a Associação Beneficente dos Artistas e o Treze Futebol Clube - também possuíram bibliotecas destinadas aos seus associados. A Associação Beneficente dos Artistas manteve a Biblioteca Antenor Navarro, a partir do ano de 1932:

\footnotetext{
Com um perfil filantrópico, relacionado à formação do trabalhador do comércio e das atividades domésticas das mulheres, a biblioteca possuiu um acervo específico para este grupo social. No ano de 1935, a biblioteca incorporou definitivamente os exemplares pertencentes ao acervo da Biblioteca do Gabinete de Leitura 7 de Setembro quando do fechamento desta última instituição. (GAUDÊNCIO, 2012, p. 119. Grifos do autor)
}

Ainda de acordo com o autor citado, os sócios dessa instituição poderiam realizar empréstimos das obras disponíveis no seu acervo. Não encontramos registro sobre até quando funcionou esse espaço de leitura ligado à Associação.

Quanto à biblioteca do Treze Futebol Clube, denominada Olívio Barreto (um dos fundadores desse clube esportivo), teve sua data de fundação registrada em nota publicada no jornal A Voz da Borborema, em maio de 1938; portanto, dois meses após o marco inicial da biblioteca pública do município.

O segundo aspecto importante no texto de Honorio de Mello diz respeito às justificativas para que se crie uma biblioteca: de um lado, a necessidade de que se atinja, culturalmente, o mesmo desenvolvimento que se acreditava ter alcançado na economia: "Campina Grande necessita de uma vida intelecttual á altura de sua vida econômica". Em outras palavras, a biblioteca seria símbolo desse progresso, servindo de evidência de que a cidade progredia em todos os setores e que a sua população era não apenas economicamente exitosa como culturalmente desenvolvida (tinha, assim, ares de ilustração que a colocavam lado a lado dos grandes centros).

De outro lado, há também a própria existência de um público que anseia por uma biblioteca. Neste aspecto, fica claro que o movimento em prol da fundação da biblioteca é iniciado por uma parcela da população cujos integrantes são identificados como intelectuais, representados "pelo intelectual n. 1 da cidade", a quem se deveriam somar os "jovens estudiosos", segundo palavras do jornal. Ou seja, não se trata, em princípio, de uma solicitação que envolva várias camadas da população campinense, mas é na verdade uma iniciativa dirigida a atingir os anseios de pessoas específicas: estudantes ("já conta por milha o número de escolas"), jornalistas ("tem já um bom 
jornal") e profissionais liberais ("professores, advogados, médicos"), pois "tudo isto reclama uma biblioteca".

No entanto, a justificativa para essa ação, como se discutirá posteriormente, mantém relação com esse projeto de transformar Campina em uma cidade progressista e moderna. Para tanto, embora tenha surgido para atender "toda uma geração [que] estava intellectualmente desamparada", vinculada à camada letrada da população, a biblioteca precisará alcançar cada vez mais cidadãos a fim de atingir seu fim último de educar para modernizar.

Nesse aspecto, os interesses subjacentes à fundação da biblioteca estão de acordo com o que se registra em relação a outras grandes bibliotecas, pois elas também não foram iniciativa das camadas mais desprestigiadas da população. Contudo, elas surgiram, como no caso da Biblioteca Pública da Bahia, por exemplo, com o disfarçado propósito de educar os cidadãos e contribuir, como consequência, para um maior desenvolvimento local (SOARES, 2011).

Assim, de um lado, a Biblioteca Pública Municipal de Campina Grande parece surgir, no discurso dos letrados, para coroar um suposto desenvolvimento (cultural e econômico) já alcançado pela cidade, mas ainda insuficiente. Ela seria, então, um símbolo dessa condição contraditória representada em duas imagens diferentes: uma, de cidade em pleno desenvolvimento; outra, de cidade que precisa se adaptar ao modelo de modernidade adotado pelos grandes centros. Para alcançar o propósito de colocar Campina entre as cidades mais desenvolvidas, não bastava, como dissemos, a reforma urbanística. Alargar ruas, alinhar casas e calçadas, entre outras ações, precisava estar em consonância com "um ambiente intellectual mais arejado e mais lucido", conforme defendido no texto citado. Transferia-se, então, a noção de "arejamento", aplicada aos espaços urbanos, para um "arejamento" de ideias; essa transferência resultava no desejo de que houvesse mudanças também no ambiente intelectual, que deveria deixar para trás discursos retrógrados e tradicionais para encher os pulmões com o que há de mais "moderno" em ser morador de uma cidade progressista como Campina pretendia ser.

Assim, é como símbolo que a biblioteca surge no contexto campinense e esse é o aspecto destacado no texto publicado em $A$ Voz da Borborema: havia um cenário favorável para a criação de uma biblioteca e esta seria mais um símbolo do progresso apresentado como evidente no discurso dos letrados da cidade. Ao mesmo tempo, poderia servir de ferramenta para a disseminação dos ideais da elite letrada, embora esse objetivo não fosse declaradamente assumido, mas implicitamente percebido na escrita desse grupo social.

\section{Quando a Biblioteca Pública Municipal de Campina Grande-PB vira notícia}

Poucos meses após a publicação do texto de Honorio de Mello em $A$ Voz da Borborema, foi fundada, em 09 de março de 1938, a tão esperada Biblioteca Pública Municipal de Campina Grande, através de um projeto de lei assinado pelo prefeito da cidade, Bento Figueiredo. Embora não tenhamos obtido acesso direto à lei de fundação, que não foi localizada porque o arquivo da Câmara Municipal da cidade guarda documentos datados a partir de 1947 e a biblioteca também não possui uma cópia da lei, a data da fundação é confirmada por diversos outros registros em jornais que deram destaque a esse ato do prefeito, especialmente o jornal A Voz da Borborema, que recupera o decreto oficial publicando-o no mesmo dia em que a biblioteca foi inaugurada. 
A história da Biblioteca Municipal de Campina Grande, desde a sua fundação até os dias atuais, apresenta muitos aspectos em comum com a história de outras bibliotecas brasileiras ${ }^{2}$, especialmente quanto ao descaso das autoridades responsáveis por manter esses espaços de leitura em boas condições de funcionamento, mas também no que diz respeito à escassez de documentos que registrem seu percurso. E essa inexistência de documentos que registrem a história desses espaços não é privilégio das instituições mais antigas: mesmo as mais recentes também prescindem dessa documentação. A Biblioteca de Valinhos-SP, cuja história foi recuperada por Latância (2011), também está repleta dessas lacunas, apesar de sua inauguração ter se dado em 1971 (o que a coloca entre as instituições mais jovens desse setor). Segundo a pesquisadora, numa primeira visita à Biblioteca ela constatou "[...] uma total ausência de documentos que pudessem contar a criação e constituição deste espaço ao longo do tempo. A Biblioteca nada tinha sobre sua própria história" (LATÂNCIA, 2011, p. 17). Essa realidade a obrigou a buscar outras fontes que pudessem ajudá-la a reescrever a história daquele espaço de leitura.

Como afirmamos anteriormente, foi através de publicação feita em $A \operatorname{Voz} d a$ Borborema que tivemos acesso ao texto do decreto oficial, assinado pelo prefeito, documento cujo texto recuperamos parcialmente a seguir:

O Prefeito Municipal de Campina Grande, usando das atribuições próprias do
seu cargo e considerando que o poder público deve prover meio de cultura
geral do povo;
considerando que a cidade de Campina Grande se ressente da falta de
biblioteca pública;
considerando que, pelo espírito do novo regime constitucional, a cultura do
povo brasileiro deve preocupar a mente dos dirigentes, antes de qualquer
outro empreendimento material, DECRETA

Art. 1 - Fica creada, pelo presente Decreto, a Biblioteca Municipal, que será franqueada ao público. (Decreto n. 12, assinado por Bento Figueiredo e publicado em A Voz da Boborema no dia 09/03/1938).

O "novo regime constitucional" mencionado no decreto é o Estado Novo, instituído no final de 1937 com o golpe que colocou Getúlio Vargas no poder e que ficaria em vigência até 1945. Embora o decreto assinado pelo prefeito de Campina Grande reconheça, em consonância com o "novo regime constitucional", a importância de incentivar a cultura, é preciso ressaltar que não se tratava de qualquer cultura, mas aquela valorizada por uma elite intelectual e que estivesse de acordo com os valores da época, mas, principalmente, com o projeto de modernização do país e de controle do povo pelo governo. Nesse sentido, o projeto de uma biblioteca se encaixa bem: primeiro, porque serviria como instrumento para propagar as ideias da elite intelectual (que, em muitos casos, foi fundadora ou iniciou o movimento de fundação de instituições dessa natureza); e segundo porque estava previsto, na constituição de 1937, o incentivo à criação de instituições culturais sob a justificativa de oferecer formação ao

\footnotetext{
${ }^{2}$ Como, por exemplo, a Biblioteca Pública da Paraíba, fundada em 1857 e vinculada, nesse início, ao Lyceu Paraibano. Nas diversas mensagens dos presidentes da província e nos relatórios dos diretores da instrução pública elaborados desde a fundação até o início dos anos 1900, é possível registrar as constantes reclamações em relação à falta de livros e de estrutura nessa biblioteca. As condições em que ela se encontrava permitiam, inclusive, que por diversas vezes algumas autoridades se perguntassem se, de fato, seria possível dizer que havia uma biblioteca na Paraíba, já que ela não funcionava a contento. Ver, sobre esse assunto, Ferronato (2012) e Menezes (1983).
} 
povo, mas cujo objetivo principal, não explicitado, era construir uma imagem positiva do governo vigente. A partir desse ponto de vista oficial, muitas bibliotecas foram criadas nos diversos Estados brasileiros, durante esse período (LEITÃO, 2011).

Se, por um lado, o governo aparecia como o grande incentivador da cultura, por outro, aperfeiçoou as formas de censura através da criação de órgãos como o Departamento de Imprensa e Propaganda (DIP) e o Instituto Nacional do Livro (INL). Este último, embora não tenha surgido para atuar como órgão censor, foi o responsável pelo controle da produção e circulação de livros durante o governo Vargas. Além de decidir pela publicação ou não de uma obra ou jornal, esses órgãos também determinavam o teor dos textos, seu tema e posicionamento ideológico (principalmente em relação às decisões governamentais).

Em pesquisa sobre a censura em relação às bibliotecas públicas, na Era Vargas e Regime Militar, Leitão (2011) conclui que as bibliotecas não eram alvo da censura, uma vez que não havia controle direto sobre as obras que compunham os acervos ou ordens expressas para a sua retirada do alcance do público leitor. Mas, se por um lado não havia preocupação direta com elas, por outro lado, as remessas do INL eram as principais responsáveis pela formação do acervo dessas bibliotecas. Sendo assim, o controle do que se lia ou do que era oferecido como leitura aos usuários era, indiretamente, exercido, já que apenas os livros aprovados pelo INL poderiam circular e eram adquiridos para envio àquelas instituições.

$\mathrm{O}$ ato de fundar uma biblioteca em Campina Grande encontra, então, respaldo político oficial, além de um terreno propício no âmbito social (tendo em vista a ausência de bibliotecas na cidade e o anseio da elite intelectual). Todo esse contexto serve de justificativa no documento assinado pelo prefeito Bento Figueiredo, no ato de fundação da biblioteca campinense.

Além de publicar os documentos oficiais relacionados à biblioteca (tais como o Decreto já mencionado e as portarias de nomeação do diretor e dos demais funcionários), o jornal $A$ Voz da Borborema registra a fundação dessa instituição através da seguinte notícia:

\section{Bibliotheca Municipal}

Por decreto divulgado em nossa edição de hoje, o prefeito Bento Figueirêdo, houve por bem brindar a sua terra com a fundação de uma bibliotheca publica, que tem por sede o salão principal do prédio onde funcciona esta folha.

A novel instituição, que vem merecendo applausos de toda a nossa gente culta, será solemnente inaugurada hoje mesmo, ás 16 horas, em homenagem á data natalícia do illustre campinense que tão sabiamente vem governando a Parahyba.

É uma homenagem, realmente, expressiva e condigna prestada, neste dia tão significativo para Campina Grande, ao Sr. Interventor Federal, visto como a maior satisfação de s. excia. tem sido sempre ver realizadas obras que tenham por escopo o bem de seus conterrâneos.

Incalculável é o proveito que resulta, num meio como o nosso, de uma instituição dessa natureza. Não só proporciona horas de sadio deleite, como offerece, aos espíritos ávidos de conhecimentos, todo o elemento necessário á sua elevação cultural.

Animado dessa convicção e inflammado de enthusiasmo em face della, é que o prefeito Bento de Figueirêdo, num gesto que muito o recommenda ao apreço daqueles que não são alheios ás coisas da intelligencia, fundou a Bibliotheca Municipal e com um carinho todo especial para com a mesma, envida esforços no sentido de incentivar o seu desenvolvimento. 
É de ver, pois, que a culta população de Campina Grande, que tão bem comprehende a magnitude dessa nobre idealidade, dispense à Bibliotheca Municipal todo o seu apoio, concorrendo assim para que ella se torne opulenta e corresponda plenamente á sua finalidade.

Deixamos vasada, aqui a expressão sincera do nosso enthusiasmo, em face do gesto tão bem comprehendido do Sr. Bento Figueiredo. ( $A$ Voz da Borborema, 09/03/1938)

Essa notícia fornece alguns dados importantes sobre as circunstâncias da fundação da biblioteca. O primeiro deles diz respeito ao local onde ela foi, inicialmente, instalada: "o salão principal do prédio onde funcionava esta folha", ou seja, no mesmo prédio de $A$ Voz da Borborema, situada na Rua Afonso Campos, número 70, no centro da cidade. Assim como ocorreu com outras bibliotecas brasileiras, a de Campina Grande também não funcionava em um prédio próprio e adaptado corretamente para esse fim, uma vez que dividia espaço com o jornal. Essa ausência de um lugar apropriado para a instalação de uma biblioteca é uma constante na história dessas instituições no Brasil.

A Biblioteca Pública da Bahia, por exemplo, foi inaugurada no dia 13 de maio de 1811, em homenagem ao príncipe regente, que aniversariava nesse dia. Foi uma iniciativa do intelectual baiano Pedro Gomes Ferrão Castellobranco, logo acatada por Dom Marcos de Noronha e Britto, então governador da Capitania da Bahia. Contudo, assim como ocorreu com a Real Biblioteca de Portugal que daria origem à Biblioteca Nacional Brasileira (SCHWARCZ, 2002), a iniciativa política de fundar uma biblioteca em Salvador não significava que havia uma estrutura pronta para recebê-la. Uma das primeiras questões que preocupavam o seu fundador era: onde instalá-la? A decisão inicial foi de que ela passasse a ocupar a antiga Livraria do Colégio dos Jesuítas, situada em cima da sacristia da igreja hoje conhecida como Catedral Basílica (SOARES et. al., 2011). Como era de se esperar, a biblioteca cresceu e o espaço se tornou inapropriado para acomodar o acervo e os leitores que a procuravam. O prédio era antigo e a falta de reparos resultou no desabamento do telhado, em 1846. Pela falta de lugar próprio, ela passou por sucessivas transferências e manteve essa peregrinação durante mais de 100 anos da sua existência, a despeito dos constantes apelos dos seus diretores. Ela só teria sua primeira sede própria entregue no ano de 1919.

Trajetória semelhante teve a primeira Biblioteca Pública da Paraíba, fundada em 1857 na então cidade da Parahyba, atual João Pessoa. Os diversos relatórios dos presidentes da província no final do século XIX e as mensagens do início do século seguinte registram, para além das tão conhecidas críticas às péssimas condições da biblioteca, o fato de que ela enfrentou períodos até mesmo de fechamento, como o ocorrido no ano de 1913, quando teve que ceder o prédio para dar lugar à Secretaria do Governo, devido à reforma realizada no Palácio do Governo. Na mensagem de 1913, apresentada por João Pereira de Castro Pinto à Assembleia Legislativa do Estado da Parahyba, lê-se o seguinte:

Esta mesma preocupação mereceu-me a Bibliotheca Pública do Estado, simulacro de repartição pública, triste exemplo de decadência em um tão precioso ramo do serviço administrativo, não obstante o zelo esclarecido de alguns cidadãos a quem se tem confiado a respectiva direcção.

Encontrei-a nas mais desoladas condições, méro pretexto de verbas orçamentárias, tão alheia e inútil ao público legente, que nem mesmo os jornais do paiz se encontram alli regularmente collecionados.

Grande parte das obras, dadivosamente offerecidas pelos particulares, truncadas, parando incertamente, em mãos desconhecidas, os volumes que de 


\begin{abstract}
pouco servirão a esses depredadores impunes da Fazenda Estadoal, habito aliás menos raro do que parece nos nossos costumes.

Fez-se selecionar os livros que ainda podiam ser utilizados, organisou-se a relação dos restantes, adquiram-se novos.

Uma circunstância de força maior interrompeu essa medida por se ter transferido a Secretaria do Governo para o predio onde funcciona a Bibliotheca, enquanto não se acabam as obras a que se procede no Palacio do Governo.

É bem possível que nesses próximos mezes tenhamos uma Bibliotheca installada convenientemente, que satisfaça ao publico, correspondendo às exigencias de um tão importante instituto de cultura social ${ }^{3}$. (1913, p. 13-14, grifos nossos)
\end{abstract}

Se os livros doados pela população estão mal conservados, não há "nem mesmo os jornais do paiz", a biblioteca se mostra "alheia e inútil ao público legente" e se configura, na opinião de Castro Pinto, em um "simulacro de repartição pública", pois não cumpre em nada seu papel. Assim, as péssimas condições em que se encontrava a Biblioteca, descritas na mensagem citada, terminam por autorizar sua desativação a fim de que o prédio seja utilizado de maneira mais útil pelo Estado.

Segundo informações divulgadas na página do Fundação Espaço Cultural (FUNESC), disponível na internet ${ }^{4}$, anos depois, em 1939, a biblioteca funcionou em um prédio na Av. Gal Osório, no centro de João Pessoa, e foi transferida para o endereço atual (nas dependências do Espaço Cultural) apenas em 1982, por determinação do governador Tarcísio Burity. Neste ano, passou a atender pelo nome de Biblioteca Pública Juarez da Gama Batista. Apesar de instalada em um espaço próprio, ela ainda contava com muitos dos problemas estruturais mencionados durante todos os anos de sua história; até que, em 2003, ela foi fechada para uma reforma que duraria longos sete anos. Em 21 de junho de 2010, foi reaberta ao público com uma estrutura modernizada, apropriada para garantir o conforto do público visitante e a boa manutenção do acervo (que contava então com 93 mil livros, incluindo obras em braile).

A Biblioteca Pública Municipal de Campina Grande também segue um percurso parecido. Começou a funcionar em um lugar provisório, que era ainda dividido com o jornal A Voz da Borborema. Ao longo de sua história, ela passará por sucessivas mudanças (que serão posteriormente listadas e comentadas), até ser instalada no atual endereço, no edifício Anézio Leão, situado à Rua Maciel Pinheiro e interditado para reforma desde o segundo semestre de 2012.

Contudo, a localização no centro da cidade é um fator que possivelmente facilitou o acesso da população num primeiro momento, pois a área urbana de Campina Grande não correspondia a um perímetro muito extenso (lembremos que o número de casas, segundo Câmara (1988), era de apenas 8.141 em 1938) e mesmo as áreas consideradas periféricas estavam localizadas nas proximidades do centro. A região conhecida por Mandchúria, por exemplo, onde se localizavam os bordéis e moravam muitos trabalhadores das classes menos privilegiadas (SOUSA, 2006a), ficava a cerca

\footnotetext{
${ }^{3}$ Mensagem apresentada à Assembleia Legislativa do Estado da Parahyba na abertura da $2^{\mathrm{a}}$. sessão ordinária da $7^{\mathrm{a}}$. legislatura pelo Dr. João Pereira de Castro Pinto, presidente do Estado. Estabelecimento Graphico Torre Eiffel. Parahyba do Norte, 1913. Disponível em http://www.crl.edu/brazil/provincial/paraiba.

4 Site da Fundação Espaço Cultural da Paraíba (FUNESC): www.funesc.pb.gov.br, acesso em $12 / 03 / 2013$.
} 
de 300m do largo da Igreja Matriz e este, por sua vez, estava à mesma distância do endereço inicial da biblioteca (R. Afonso Campos, 70). Além disso, há que se considerar ainda o fato de que a divisão entre centro e periferia não impedia que os cidadãos residentes em uma e outra área frequentassem mutuamente espaços das duas regiões e construíssem, com esses deslocamentos - a princípio não previstos e por vezes mesmo rejeitados/condenados em cada grupo social -, uma cartografia particular da cidade (SOUSA, 2006a). Segundo o autor, as relações de lazer e de trabalho contribuíam em grande parte para que esses grupos e as cartografias decorrentes delas dessem a Campina Grande ares de cidade múltipla, opondo-se a essa imagem de cidade bipartida entre elite e periferia, presente nos textos escritos pelos letrados campinenses.

Campina Grande aparecia, em grande parte do discurso e da propaganda das elites, ambiguamente, como um lugar em franca expansão e cheio de mazelas, mas onde o progresso e a civilização deitavam raízes. Dissecar e esquadrinhar a cidade, trazendo à tona sua diversidade, é mostrar também como as elites tentaram hierarquizar espaços e intervieram em territórios, buscando instituir valores que mantivessem o status quo, ou que o modificassem apenas superficialmente para incorporar novos grupos e interesses. (SOUSA, 2006a, p. 112)

Da mesma maneira como os cidadãos ditos "ilustres" frequentavam os espaços de socialização localizados na periferia da cidade e a recíproca também acontecia, o fato de a biblioteca estar situada no centro não deve ter sido impedimento para que pessoas moradoras de outras regiões a frequentassem. Ao menos não havia impedimento geográfico; contudo, sem dúvida, havia impedimentos de outra natureza, como o analfabetismo e a ausência de familiaridade com práticas letradas relacionadas à leitura de livros.

Outro dado que essa notícia reforça é a já mencionada relação da biblioteca com uma parcela específica da população, considerada culta pelo jornal e cujos integrantes receberam com grande reconhecimento e satisfação o ato do prefeito Bento Figueiredo: "a novel instituição vem merecendo applausos de toda a nossa gente culta". Não apenas nesta, mas em outras notícias que veremos posteriormente é recorrente o uso do adjetivo culta para se referir às pessoas a quem a biblioteca atingiu e agradou, bem como a referência a essas pessoas como intelectuais. Esse é um dado interessante porque aponta, em princípio, para uma relação entre a biblioteca e essa elite letrada da população; inclusive, como já afirmamos, o próprio movimento de sua fundação não foi fomentado pelas camadas mais humildes da população ou mesmo orientado para atingilas, e sim por um público letrado, composto por autoridades reconhecidas na área das letras (como escritores e jornalistas), como apontam indiretamente as notícias do jornal A Voz da Borborema - semelhantemente ao que ocorreu também, por exemplo, na história da Biblioteca Pública da Bahia, segundo Soares (2011).

Ainda sobre essa notícia do dia 09/03, é interessante observar que, associado ao gesto de fundação de uma instituição dessa natureza, está o reconhecimento do prefeito como um generoso benfeitor, por parte daqueles que "não são alheios às coisas da inteligência". Além disso, verifica-se o uso da biblioteca como forma de homenagem a uma autoridade, neste caso a Argemiro de Figueiredo, o que reforça, então, o caráter simbólico que os livros, e por consequência a biblioteca, têm. Basta observar a avaliação positiva feita pelo jornal a respeito da fundação desse espaço de leitura: "Incalculável é o proveito que resulta, num meio como o nosso, de uma instituição dessa natureza. Não só proporciona horas de sadio deleite, como offerece, aos espíritos 
ávidos de conhecimentos, todo o elemento necessário á sua elevação cultural". Há, pois, nesse trecho, a valorização do ato de fundação da biblioteca e também a definição da finalidade que se atribui a ela - deleite e elevação cultural. Assim como na Campina grande e moderna as ideias deveriam ser agora "arejadas", o deleite também deveria ser "sadio", ou seja, estar relacionado a práticas consideradas saudáveis. Mais uma vez é possível perceber aí a transferência/influência do discurso médico-higienista aplicado a diversas áreas naquele período e interessado em propagar novos hábitos com base na ideia de saúde e limpeza. As horas de lazer deveriam ser utilizadas para o divertimento, desde que este fosse considerado "saudável" e, consequentemente, "útil"; estavam excluídas desse rol de "sadio deleite", pois, as já conhecidas práticas populares de se entregar às bebedeiras nos bares da cidade e aos jogos (como o bilhar).

Em edição posterior (do dia 12/03/1938), é feito o relato de toda a solenidade de inauguração da biblioteca, tendo em vista que ela se deu por ocasião do aniversário de Argemiro de Figueiredo e junto às comemorações relativas a essa data. Transcrevemos a seguir trechos desse relato que, embora extenso, registra informações importantes sobre esse momento da história da biblioteca:

\section{A inauguração da Bibliotheca Municipal}

Entre as solenidades levadas a effeito, em homenagem ao transcurso do natalício do governador Argemiro de Figueirêdo, destacamos a inauguração da Bibliotheca Municipal, no salão onde vinha funcionando a redacção desta folha, não só pelo brilhantismo de que a mesma se revestiu, mas, sobretudo, pela magnífica ideia do prefeito Bento Figueirêdo, fundando uma instituição que veio prehencher uma lacuna sensível, de há muito, aos espíritos bem formados, na terra campinense.

$\mathrm{O}$ acto verificou-se às 16 horas, quando já era grande a assistencia, que se compunha de pessoas do maior destaque em nossa sociedade.

A sessão, que se revestiu de muito brilhantismo, foi presidida pelo prefeito Bento Figueirêdo, tendo s. s. convidado para tomares parte na mesa os drs. Julio Rique, juiz de direito da $2^{\mathrm{a}}$. vara, nesta cidade, Edealo Sila, presidente da Associação Commercial, Hortensio Ribeiro, $2^{\circ}$. promotor publico e nosso illustre collaborador, e a professora Otilia Xavier.

O prefeito Bento Figueirêdo usa então da palavra e diz, em palavras simples, mas expressivas, do motivo daquella reunião, inaugurando por fim a Bibliotheca Municipal de Campina Grande. [...]

Após, levantou-se o dr. Hortensio Ribeiro, que pronunciou um brilhante discurso.

$\mathrm{O}$ illustre homem de letras fez um retrospecto da vida social campinense, salientando os vultos que igualmente ao prefeito Bento Figueirêdo idealizaram e fundaram bibliothecas em nossa terra, entre as quaes o "Gabinete de Leitura 7 de setembro", verdadeiras escolas de instrucção, que não obstante muito terem concorrido para maior incremento das cousas do espírito, no meio ambiente, feneceram por nunca lograrem merecer as attenções dos poderes municipaes. [...]

A seguir o prefeito Bento Figueirêdo manda que o seu secretário, professor Almeida Barreto, leia o Decreto da creação da Bibliotheca e as portarias de nomeação dos seus directores, o que foi feito sob a attenção geral da assistencia.

Quando o prof. Almeida Barreto articulou o nome do professor Mauro Luna, escolhido pelo sr. prefeito para director da Bibliotheca, a sua voz abafada por estrepitosa salva de palmas.

Terminando o secretario do prefeito a leitura dos actos officiaes, discursou o prof. Luiz Gil, director do nosso confrade "O Rebate".

O nosso collega de imprensa expressou a sua satisfação em face da nobre iniciativa do prefeito Bento Figueirêdo, referindo-se a seguir com palavras 


\begin{abstract}
commovedoras á escolha do professor Mauro Luna para director da Bibliotheca Municipal, que foi, como elle afirmou, das mais acertadas e justas.

[...] É quando, commovido, ergue-se o prof. Mauro Luna, sob applausos da assistencia. [...]

Referiu-se á predilecção do illustre chefe parahybano para com os intellectuaes, a quem, sempre, atendera com especial deferencia, no sentido de facilitar-lhes o exito merecido, - a predilecção esta manifestada, também, pelo prefeito campinense, um enthusiasta das coisas do espírito. A prova estava na fundação da Bibliotheca Municipal, fructo embrionário que seria, mais tarde, um motivo de orgulho para Campina Grande. [...] (A passagem do anniversario natalício do interventor Argemrio [sic] de Figueirêdo. A Voz da Borborema, 12/03/1938).
\end{abstract}

Neste texto verifica-se o mesmo discurso enaltecedor sobre o gesto do prefeito, o que fica evidenciado pela escolha dos adjetivos empregados para se referir à sua decisão, avaliada como uma "magnífica ideia", que vem preencher uma "lacuna sensível" na cidade, lacuna esta sentida pelos "espíritos bem formados". Em outras palavras, havia um espaço em branco nas letras campinenses, a ser preenchido pela biblioteca. São reforçadas ainda duas informações importantes: a existência de instituições de leitura anteriores, mas que não se mantiveram devido à falta de investimento do governo, e a forte ligação entre o gesto de fundação da biblioteca e a elite intelectual campinense, como se pode observar no último parágrafo, no qual a biblioteca é colocada como prova de que o prefeito Bento Figueiredo segue o exemplo de Argemiro de Figueiredo na "predilecção do illustre chefe parahybano para com os intelectuaes". Aliás, o próprio prefeito é descrito como um illustre homem de letras pelo jornal.

Outro homem ilustre que aparece vinculado à história inicial da Biblioteca Municipal nesse primeiro momento de sua existência é Mauro Luna, que deixa o cargo de fiscal do município junto à empresa de Luz e Força para assumir a direção da Biblioteca, segundo as portarias número 12 e 13, publicadas na mesma edição de 12/03/1938, ora comentada. Mauro Luna (1897-1943) foi professor de duas importantes escolas particulares de Campina Grande (o Colégio Pio XI e o Imaculada Conceição/Damas, tendo sido o autor do hino deste último educandário); fundou, em 1915, o jornal Renascença, que circulou por três anos na cidade; aos quinze anos, tornou-se redator do jornal A Voz da Borborema e em 1924, conforme já mencionado, publicou o elogiado livro Horas de Enlevo; em 1942, foi eleito membro da Academia Paraibana de Letras ${ }^{5}$. Era, portanto, um nome que tinha ligação direta com as elites culturais e políticas da época, já exercendo cargo no governo municipal antes de ser nomeado para a direção da biblioteca.

Para finalizar, é apresentada, nesta mesma matéria jornalística, uma lista das pessoas que compareceram à solenidade de instalação da biblioteca, que conferiram, segundo o jornal, "muito brilhantismo" à sessão, pois esta foi prestigiada por "pessoas do maior destaque na sociedade". De fato, na lista publicada estão registrados nomes de figuras ilustres da história de Campina Grande, entre professores, jornalistas e políticos:

[...] Damos abaixo, pela ordem, os nomes dos presentes á installação da Bibliotheca Municipal e que assignaram a respectiva acta:

\footnotetext{
5 Informações divulgadas pelo blog Retalhos Históricos de Campina Grande, disponível em: http://cgretalhos.blogspot.com.br/2010/02/o-professor-mauro-luna.html\#.U079PfldWip consultado em 30/março/2014.
} 
Prefeito Bento Figueirêdo, dr. Julio Rique, dr. Edesio Silva, dr. Hortensio de Souza Ribeiro, professora Otilia Xavier, dr. Severino Barbosa Leite, acadêmico Hiaty Leal, professor Severino Loureiro, dr. Acacio Figueirêdo, Genaro Cavalcanti, Abelardo Fonseca, por si e pelo Banco do Commercio, João da Camara Moura, dr. Antonio Telha de Mendonça, dr. José de Farias, dr. Aloysio Affonso Campos, dr. João Tavares Cavalcanti, José Pereira de Castro, cel. José Mauricio da Costa, Mario Pinheiro de Mendonça, acadêmico Anastacio Honorio de Mello, João Barbosa da Silva, João Climaco Ximenes, Antonio Borges da Costa, dr. Luiz Gomes Peixe, Octacilio Gomes, Tertuliano Barros, poeta Silva Andrade, Gervasio Ferreira da Silva, professor Luiz Gil, Antonoi Correia Lima, pelo gerente do Banco do Brasil e a A. E. no Commercio, Octacilio Colaço da Costa, jornalista José Lopes de Andrade, Luiz Sodré Filho, jornalista Pedro Aragão, professor Antonio de Oliveira, Severino Rodrigues de Almeida, professora Apolonia de Amorim, senhoritas Antonieta Macedo, Inalda Macêdo e Francisca Rosado, professora Maria Amenaíde Pimentel, professor Mauro Luna, por si e pelo sr. José de Barros Ramos, Possídio Rodrigues de Almeida e jornalistas Raymundo Vianna, Adaucio Rocha e Elyalo Nepomuceno. (A passagem do anniversario natalício do interventor Argemrio [sic] de Figueirêdo. A Voz da Borborema, 12/03/1938).

A fundação da biblioteca foi notícia também no jornal $A$ União $o^{6}$, de 23 de março de 1938:

Por iniciativa do operoso prefeito Sr. Bento de Figueiredo, vém a ser fundada, em Campina Grande, a Biblioteca Municipal, que terá papel saliente na educação e ilustração daquela cidade.

A inauguração da Biblioteca Municipal de Campina Grande teve lugar no dia 9 corrente, em homenagem à data aniversária do interventor Argemiro de Figueiredo.

Somente aplausos merece o ato do prefeito Bento de Figueiredo e folgamos de regista-los para que seja exemplo vivo de patriotismo e compreensão da verdadeira noção educativa de que, na época presente, todos se devem capacitar em beneficio da coletividade.

Os objetivos - educação e ilustração -, atribuídos à biblioteca nesta notícia divulgada em $A$ União, são diferentes em relação àqueles veiculados por $A \operatorname{Voz} d a$ Borborema, citados anteriormente, ou seja, a notícia é construída a partir de outra perspectiva, destacando outras funções para a biblioteca inaugurada. Ainda que não tenha nascido vinculada a uma instituição de ensino, como ocorreu com a primeira biblioteca pública fundada em João Pessoa, segundo A União, a instituição campinense surge aos olhos da sociedade com esse propósito, reforçado no primeiro e último parágrafos do texto. A biblioteca seria, então, um dos instrumentos para garantir a educação do indivíduo e, assim, beneficiar a coletividade. Ou seria, ao menos, um instrumento para garantir que se construísse uma imagem positiva do governo vigente, reconhecido a partir desse ato como uma administração preocupada em oferecer cultura e contribuir para o desenvolvimento da população. Como se vê, nos dois textos jornalísticos que noticiam a inauguração da Biblioteca Municipal, há duas representações de biblioteca subjacentes: de um lado, a biblioteca aparece como símbolo de ilustração e desenvolvimento intelectual, destinada à "gente culta", aos "espíritos ávidos de conhecimento", que reconhecem seu valor e aplaudem esse gesto por verem nela um mecanismo de "sadio deleite" e também de "elevação cultural". De

${ }^{6}$ Jornal disponível no acervo do Arquivo Público da Paraíba (João Pessoa-PB). 
outro lado, na matéria veiculada em A União, a biblioteca aparece como instrumento de educação, uma vez que a "capacitação" do povo é premente para o "benefício da coletividade". Em ambos os casos, tem-se uma proximidade com a visão idealizada a respeito dessas instituições.

Cabe, portanto, retomar parte do pensamento de Chartier (2002, p. 17) sobre a noção de representação:

\begin{abstract}
As representações do mundo social [...], embora aspirem à universalidade de um diagnóstico fundado na razão, são sempre determinadas pelos interesses de grupo que as forjam. Daí, para cada caso, o necessário relacionamento dos discursos proferidos com a posição de quem os utiliza. [...] As percepções do social não são de forma alguma discursos neutros: produzem estratégias e práticas (sociais, escolares, políticas) que tendem a impor uma autoridade à custa de outros, por elas menosprezados, a legitimar um projeto reformador ou a justificar, para os próprios indivíduos, as suas escolhas e condutas [...].
\end{abstract}

Em certa medida, as duas representações a respeito da Biblioteca Pública Municipal de Campina Grande, veiculadas implicitamente nos dois jornais não são neutras, mas servem para justificar e legitimar, nas palavras de Chartier (2002), o projeto reformador da sociedade, simbolizado pela inauguração dessa instituição. Assim, ao surgir nesse contexto de busca por modernidade e passar a, indiretamente, tomar parte em um projeto de cidade progressista, a biblioteca se transforma a um só tempo em ferramenta e símbolo desse processo que visava a garantir a expansão do progresso por todas as áreas, incluindo a educação. Não basta ser, portanto, a cidade do comércio vitorioso, é preciso ser também a cidade "ilustrada", para que ela tenha uma imagem com a qual os letrados (não necessariamente relacionados a atividades de comércio) possam se identificar e da qual possam se orgulhar. Essa perspectiva é trazida dos modelos adotados por outras grandes cidades brasileiras, a exemplo do Rio de Janeiro. Segundo Oliveira (2009, p. 194),

\footnotetext{
Esse conjunto de representações elaborado por uma parte da intelectualidade brasileira são "regimes de verdade" que possuem forças na construção de novos comportamentos, formando um tipo de governo dos homens que provoca descontinuidades com os padrões antigos de sociabilidade. $\mathrm{O}$ futuro era imaginado num contexto de louvação à modernidade, vista e dita como o desejo de emancipação ou obscurantismo e dos preconceitos.
}

Ao mesmo tempo em que aparece como um discurso novo, esse ideal de educação/ilustração como a solução para todos os males e o uso de bibliotecas como símbolo dessa aparência de sabedoria é, na verdade, bastante antigo e muito recorrente na história dessas instituições. Com a biblioteca de Campina Grande parece não ter sido diferente. Se não podemos afirmar com toda certeza que este foi o principal propósito de sua criação (já que identificamos através dos textos jornalísticos citados ao menos dois discursos em relação a esse aspecto, os quais não são excludentes), é interessante pensar sobre a opção do governo de inaugurar uma biblioteca pública num município onde faltavam muitos outros serviços básicos para a população, como abastecimento regular de água e energia elétrica.

Nesse contexto de falta de energia elétrica, apenas a inauguração da biblioteca não se mostra suficiente para que de pronto passe a ser utilizada pela população, que vê o horário de visitação limitado pela falta de luz naquele espaço, conforme se pode verificar em notícia publicada em A Voz da Borborema: 
Hoje, que a administração brilhante do snr. Bento de Figueirêdo criou para o povo campinense uma obra de incomparável valor, intelectual - a Biblioteca Pública Municipal - somos, a maior parte das noites, impossibilitados de freqüenta-la, dada a deficiência de luz. (A Voz da Borborema. De Mal a Peor a Luz de Campina. 14/05/1938)

Assim, se por um lado as luzes da ilustração começam a se fazer presentes e se verem reforçadas pela existência de uma biblioteca, por outro lado, o cumprimento desse objetivo de promover o conhecimento esbarra na ausência de condições básicas apropriadas para isso, como a luz elétrica. Contudo, Bento Figueiredo é apontado como um dos grandes reformadores da cidade de Campina Grande, juntamente a outro prefeito, Verniaugd Wanderley, que administraram o município entre as décadas de $30 \mathrm{e}$ 40 e se empenharam por dotar Campina com ares de modernidade (CABRAL FILHO, 2010), o que inclui reformas desde a arquitetura da cidade, passando pela melhoria nos serviços básicos (como água e energia elétrica) e pela criação e construção de instituições educacionais/culturais, entre as quais, sem dúvida, figura a biblioteca municipal.

Essas ações são reconhecidas pela população campinense, mas é na voz da imprensa que elas tomam aparência de propaganda política ao serem amplamente elogiadas pelos letrados que publicam nos jornais. Durante todo o ano de 1938, várias edições do jornal A Voz da Borborema divulgam matérias elogiosas ao governo de Bento Figueiredo e colocam a biblioteca como um dos principais empreendimentos do seu primeiro ano de administração, como se pode verificar, por exemplo, no texto a seguir:

Apologia á Administração do Sr. Bento Figueiredo

SEVERINO ALMEIDA

Incontestavelmente tem sido a administração do Snr Bento Figueiredo á frente do povo campinense, digna de incalculáveis elogios.

Dentre as muitas realisações de s.s. salienta-se a criação, ultimamente, da Biblioteca Pública, cujo valor é incomparável para um povo que sabe tão bem reconhecer o valor deste estabelecimento de cultivo intelectual.

Campina Grande, cidade que hoje pôde ser contada no número das civilisadas, não podia, por mais tempo, continuar privada dessa incomparável fonte de educação intelectual, para aquêles que bem sabem empregar suas horas desponiveis.

Mas tudo tem o seu dia felis, que ficará gravado nos lauréis da história, como mais um degrau galgado em seu progresso. O dia 9 de março, não obstante já encerrar em si uma grande epopéia pela passagem do aniversário do seu grande filho e bemfeitor Argemiro de Figueiredo, será, de hoje por deante, mais lembrado ainda, por ter sido a data da criação do que tanto Campina necessitava.

Hoje, já não mais se dirá "Campina não tem a onde se empregarem as horas de descanço"; quem souber dar valor ao que é bom e proveitoso, certamente não deixará de ir a uma Biblioteca, onde nada mais fará, do que colher maravilhosos frutos, para ir a um bilhar, perder não tão somente o tempo, como o dinheiro, sem dalí tirar o menor proveito.

O gesto do s. s. criando a Biblioteca Pública Municipal, foi um dos mais louváveis e louvável também seria, para todos os campinenses que bem sabem reconhecer o valor de tão rica fonte de sabedoria, a oferta de um livro apenas, para em pouco tempo termos um avultadíssimo número de obras, que imortalizariam, por sua oferta o reconhecido povo dessta terra de visões tão largas para os degraus do progresso. (A Voz da Borborema, 10/11/1938) 
Não por acaso, o texto tem no título a palavra apologia e, assim como os demais publicados no jornal, exalta os feitos do governo naquele primeiro ano de mandato. Mas merecem atenção principalmente as expressões utilizadas para se referir à biblioteca, as quais revelam uma representação da leitura e da biblioteca que se aproxima da visão idealizada: "estabelecimento de cultivo intelectual, fonte de educação intelectual e fonte de sabedoria", que representa para Campina Grande "mais um degrau galgado em seu progresso" e que garante à cidade o seu pertencimento ao "número das civilisadas". A BPMCG é descrita, portanto, como símbolo de ilustração e progresso do município; e o prefeito, como responsável pelo avanço de "que tanto Campina necessitava", é o seu grande benfeitor, imortalizado por esse gesto. Por outro lado, algumas expressões utilizadas deixam entrever a atribuição de diferentes funções da biblioteca junto aos seus leitores, pois além de ser considerado um lugar de desenvolvimento intelectual (como ilustram as expressões "fonte de educação intelectual" e "fonte de sabedoria"), ela também se destina àqueles "que bem sabem empregar suas horas desponíveis" ou por quem sabe "dar valor ao que é bom e proveitoso", mas antes não tinha onde empregar as "suas horas de descanço". Ou seja, a biblioteca é vista como uma alternativa de lazer, mas principalmente um lazer que confere ao seu frequentador um status de alguém que sabe reconhecer o que é bom e proveitoso - quem não lê e não vai à biblioteca, portanto, não sabe.

Por consequência, a leitura é vista também como uma atividade a ser desenvolvida nas horas de descanso porque é considerada proveitosa, quando comparada a outras, geralmente realizadas nas horas de ócio, como o bilhar, por exemplo. Nesse sentido, a instituição poderia se tornar um instrumento a mais no projeto de tornar Campina realmente "grande", pois as horas de lazer seriam aproveitadas de maneira "útil" na leitura de textos que possivelmente valorizariam os ideais morais, educativos e comportamentais defendidos pela camada letrada da população. Talvez por isso, ao ver que o uso inicialmente previsto por ela no ato de fundação da biblioteca não estava sendo respeitado, essa mesma elite letrada passe a elaborar, anos depois, duras críticas dirigidas às práticas "ilegítimas" realizadas pelos leitores naquele espaço, corrompendo-o (ESPÍNDULA, 2015).

No final de 1938, o jornal publica um texto de avaliação do governo de Bento Figueiredo e, na área de cultura, destaca:

\begin{abstract}
A municipalidade campinense tem a preocupação da cultura, no sentido de melhorar a situação geral do Município, elevando o nível da vida de sua densa população. É uma preocupação conciente e efetiva, que já se traduziu brilhantemente em duas realizações úteis e concretas: o Campo de Demonstração Municipal e a Biblioteca Pública. [...] Com a Biblioteca Pública, cuja utilidade é incontestável, o Sr. Bento Figueiredo quiz ir ao encontro das necessidades espirituais de uma população de 48 mil almas, entre as quais cerca de 4 mil estudantes primários e secundários. Estes espíritos em formação necessitam de fontes de saber e cumpre ao Estado Novo, em cuja comunhão a municipalidade campinense se integrou, graças à esclarecida visão do seu joven dirigente, prover estas inteligências sequiosas dos necessários meios, no intuito de aparelhar as gerações que conduzirão a nacionalidade amanhã. (A Voz da Borborema, 14/12/1938)
\end{abstract}

Aos poucos, então, a biblioteca de Campina Grande se vai transformando, cada vez mais intensamente, em símbolo de progresso e desenvolvimento intelectual. Mesmo quando o jornal se refere a ela como um lugar propício para empregar as horas de lazer, 
ele só o faz porque esse lazer é avaliado como bom e proveitoso. Assim, não tardaria para que essa instituição fosse mais explicitamente associada à educação e tivesse sua utilidade ressaltada. Ao longo da análise dos textos publicados acerca da fundação da BPMCG, pudemos observar que esta instituição surge como anseio de uma elite intelectual, mas, dentro de alguns meses, aparece retratada no jornal como uma das necessidades espirituais de uma população de 48mil almas, ou seja, como anseio de toda a população do município. Reforça-se, assim, seu caráter público no sentido que conhecemos hoje (da universalidade do acesso), mas principalmente o início da relação dessa instituição com um público leitor vinculado à educação formal, pois o texto destaca, sobretudo, a existência de 4 mil estudantes primários e secundários, que necessitam de uma instituição para lhes fornecer as ferramentas necessárias à sua formação e, em última instância, para melhorar o nível de vida da população campinense (conforme mencionado logo nas primeiras linhas do trecho citado). Dessa maneira o prefeito tem, então, reforçada a imagem de grande benfeitor da população ao, pioneiramente, fundar uma instituição pública dessa natureza e com essa importância.

\section{Considerações finais}

Na década de 30 dos anos XX, Campina Grande era, no discurso dos letrados que publicavam nos jornais locais, uma cidade em pleno desenvolvimento, sustentada pela cultura e comércio do algodão. Contudo, essa imagem de cidade em crescimento não condizia, em muitos aspectos, com a vida do cidadão campinense, pois Campina se ressentia com a falta de serviços básicos importantes, como abastecimento de água e fornecimento de energia elétrica regulares. As publicações nos jornais apresentavam, portanto, uma tensão entre dois discursos acerca da cidade: aquele que reconhecia e valorizava os avanços supostamente alcançados em decorrência da produção e do comércio do algodão, avanços estes que justificavam uma imagem de município em pleno desenvolvimento; e aquele que denunciava os graves problemas ainda enfrentados pela população, que não dispunha de serviços básicos para garantir-lhe condições de vida satisfatórias.

Embora aparentemente contraditórios, esses discursos, na realidade, convergiam para a defesa de um mesmo ideal: o de uma cidade moderna e bem desenvolvida. Nesse contexto, a Biblioteca Pública surgia para atender aos interesses da elite cultural da cidade: a necessidade de que se atingisse, culturalmente, o mesmo desenvolvimento que se acreditava ter alcançado na economia - "Campina Grande necessita de uma vida intelecttual á altura de sua vida econômica", como se lia no jornal daquele ano. Em outras palavras, a biblioteca seria símbolo desse progresso, servindo de evidência de que a cidade progredia em todos os setores e que a sua população era não apenas economicamente exitosa como culturalmente desenvolvida.

Há, tanto na iniciativa do prefeito de atender a aclamação de uma elite intelectual quanto na reação popular, traços de uma visão idealizada das bibliotecas, vistas como símbolos de poder e ferramentas para a educação e formação do espírito do povo.

\section{Referências}


CABRAL FILHO, Severino Cabral. Campina Grande (1930-1950): modernização, cotidiano e cultura material. In: Patrimônio e Cultura Material - Projeto História, n. 40. Junho/2010.

CÂMARA, Epaminondas. Datas Campinenses. Campina Grande-PB: Caravelas, 1988.

A cidade desejada: Campina Grande: imagens e história. In: ANDRADE, J. C. de S. et alii (orgs.). Cultura e Cidades. Campina Grande: EDUFCG, 2009.

CHARTIER, R. (org.) Práticas da leitura. São Paulo: Estação Liberdade, 1996.

Paulo, 1991.

O mundo como representação. Revista Estudos Avançados, vol 5, n.11. São

A história cultural: entre práticas e representações. 2. Ed. Algés - Portugal: DIFEL, 2002.

Formas e Sentido: Cultura escrita: entre distinção e apropriação. CampinasSP: Mercado de Letras; Associação de Leitura do Brasil (ABL), 2003.

As práticas da escrita. In: ARIÈS, P. e DUBY, G. História da Vida Privada: da Renascença ao Século das Luzes. São Paulo: Companhia das Letras, 2009.

COSTA, Fernanda Pires da. A Livraria Pedrosa - Casa do Saber: a emergência de uma cidade letrada e de leitores. Universidade Federal de Campina Grande. Programa de Pós-Graduação em História. Dissertação de mestrado. Setembro/2012.

ESPÍNDULA, Danielly Vieira Inô. Biblioteca Pública Municipal de Campina Grande$P B$ : histórias, leitores e leituras. João Pessoa-PB, 2015. 283f. Tese (doutorado). PROLING/UFPB.

FERRONATO, Cristiano de Jesus. A Biblioteca do Lyceu provincial e seus compêndios: as primeiras configurações da formação de uma biblioteca pública na província da Parahyba do Norte. In: Anais eletrônicos. IX Seminário de Estudos e Pesquisas "História, Sociedade e Educação no Brasil". Universidade Federal da Paraíba. João Pessoa - 31/07 a 03/08/2012. ISBN: 978-85-7745-551-5.

GAUDÊNCIO, Bruno Rafael de Albuquerque. Da academia ao bar: círculos intelectuais, cultura impressa e repercussões do Modernismo em Campina Grande - PB (1913-1953). Universidade Federal de Campina Grande. Programa de Pós-Graduação em História. Dissertação de mestrado. Março/2012.

LATÂNCIA, Lara Elisa. Biblioteca Municipal de Valinhos: uma história possível de ser escrita. Relatório final de pesquisa de Iniciação Científica. Universidade Estadual de Campinas. FAPESP. 2011.

LEITÃO, Bárbara Júlia Menezello. Bibliotecas públicas, bibliotecários e censura na Era Vargas e Regime Militar. Rio de Janeiro: Interciência, 2011.

MENEZES, J. R. de. História do Lyceu Parahybano. Editora Univeristária/UFPB: João Pessoa, 1983.

OLIVEIRA, Iranilson Buriti de. Alfabetizando a Rainha com o bisturi do progresso: práticas médico-higienistas e educação primária em Campina Grande (1920-1940). In: ANDRADE, J. C. de S. et alii (orgs.). Cultura e Cidades. Campina Grande: EDUFCG, 2009. 
SCHWARCZ, L. M. A longa viagem da Biblioteca dos Reis: do terremoto de Lisboa à independência do Brasil. São Paulo: Cia das Letras, 2002.

SOARES, Francisco Sergio Mota. et. al. A biblioteca pública da Bahia: dois séculos de história. Salvador-BA: Fundação Pedro Calmón, 2011. 204p.

SOUSA, Fabio Gutemberg Ramos Bezerra de. Territórios de confrontos: Campina Grande 1920-1945. Campina Grande: EDUFCG, 2006a.

SOUSA, Maria Ester Vieira de. Histórias de pesquisas em leitura. In: SOUSA, Maria Ester Vieira de, ASSIS, Maria Cristina (orgs.). Pesquisa em Língua Portuguesa: da construção do objeto à perspectiva analítica. João Pessoa: Editora da UFPB/UFPB virtual, 2011. p. 137-168.

Recebido em 15 de setembro de 2018

Aceito em 20 de dezembro de 2018 